\title{
Myocardial revascularization using on-pump beating heart among patients with left ventricular dysfunction
}

\author{
Ahmad K Darwazah ${ }^{1 *}$, Vivian Bader ${ }^{1}$, Ismail Isleem², Khalil Helwa²
}

\begin{abstract}
Objectives: On-pump beating heart technique for myocardial revascularization has been used successfully among both low and high risk patients. Its application among low ejection fraction patients is limited. The aim of our study is to evaluate this technique among patients with low ejection fraction and to compare results with offpump bypass technique.

Methods: This retrospective study includes 137 patients with ejection fraction below 0.35 who underwent isolated coronary artery bypass surgery. 39 patients underwent myocardial revascularization using on-pump beating heart $(\mathrm{ONCAB} / \mathrm{BH})$, while 98 patients had off-pump beating heart (OPCAB). Different preoperative, operative and postoperative variables were evaluated among both groups.

Results: Patients profiles and risk factors were similar among both groups, except for the number of patients undergoing redo $C A B G$ which was significantly higher among ONCAB/BH (13\% vs 3\%; $p=0.025)$. Ejection fraction (EF) varied from 10-34\%. The mean EF for patients who underwent ONCAB/BH was $28 \pm 6$ in comparison to $26 \pm 5$ for OPCAB patients $(P=0.093)$. Predicted risk for surgery according to EuroSCORE was similar among both groups $(P=0.443)$. The number of grafts performed per patient was significantly more among patients who underwent $\mathrm{ONCAB} / \mathrm{BH}(2.2 \pm 0.7$ Vs $1.7 \pm 0.7 ; \mathrm{P}=0.002)$. Completeness of revascularization was significantly greater in the ONCAB/BH patients ( $72 \% \mathrm{Vs} 46 \%, \mathrm{P}=0.015)$. The incidence of hospital mortality and combined major morbidity was more among $\mathrm{ONCAB} / \mathrm{BH}$ in comparison to $\mathrm{OPCAB}$, but the difference was not significant. However, the incidence of blood loss, ventricular arrythmias, inotropic support, ICU, hospital stay and blood transfusion were significantly greater among patients who underwent ONCAB/BH.
\end{abstract}

Conclusions: On-pump beating heart technique can be used in myocardial revascularization among patients with left ventricular dysfunction. The technique was found to be associated with better myocardial revascularization when compared with $\mathrm{OPCAB}$ technique. However, the incidence of morbidity and mortality was more than OPCAB.

\section{Introduction}

Despite the presence of different pump techniques used in surgical myocardial revascularization, the optimal method used is still controversial. No technique was found perfect to be applied to all patients. Nowadays we are confronted with different categories of patients varying from straightforward low risk cases to complicated ones due to the increase in number of elderly patients

\footnotetext{
* Correspondence: darwaz30@hotmail.com

'Department of Cardiac Surgery, Makassed Hospital, Jerusalem, Israel

Full list of author information is available at the end of the article
}

with complicated coronary anatomy and impaired left ventricular function.

The use of both conventional cardiopulmonary bypass and OPCAB among patients with impaired LVF proved its efficiency and safety [1,2]. Under certain circumstances, the application of both techniques could not be possible and even harmful to the myocardium [3].

In our present work, $\mathrm{ONCAB} / \mathrm{BH}$ technique was used to revascularize the myocardium among patients with impaired LVF. The results of such technique was compared to those who underwent off-pump beating heart.
C Biomed Central

C 2010 Darwazah et al; licensee BioMed Central Ltd. This is an Open Access article distributed under the terms of the Creative Commons Attribution License (http://creativecommons.org/licenses/by/2.0), which permits unrestricted use, distribution, and reproduction in any medium, provided the original work is properly cited. 


\section{Patients and Methods}

This study was performed retrospectively among 137 patients with isolated coronary artery bypass surgery during the period from 1999-2009. The selection of patients was based initially on their ejection fraction. Those with ejection fraction below 0.35 were included only and divided into two groups according to the technique used during myocardial revascularization. Ninety eight patients underwent $O P C A B$, while thirty nine patients had ONCAB/BH technique. Patients with combined procedure and those patients who initially underwent off-pump and converted to on-pump beating heart were excluded from the study. The decision to use either technique was made intraoperatively based on hemodynamic parameters.

Patients who could tolerate manipulation of the heart without hemodynamic deterioration to visualise target vessels underwent OPCAB revascularization. Those patients who showed hemodynamic deterioration during manipulation underwent $\mathrm{ONCAB} / \mathrm{BH}$.

Different preoperative, operative and postoperative variables were evaluated among both groups. Analysis was performed using statistical software version 13 SPSS (Chicago, IL). Data are expressed as percentages and compared using Fisher exact test. Variables are presented as mean \pm standard error using student's $t$ test. Statistical significance was assumed when $P$ value was less than 0.05 .

\section{Surgical Technique}

Exposure of the heart was performed through median sternotomy. Full heparinization was used in all patients maintaining activated clotting time $>400 \mathrm{~s}$. In patients undergoing $\mathrm{ONCAB} / \mathrm{BH}$ a standard cannulation of the aorta and right atrium was used. A full cardiopulmonary bypass with normothermia was used. Anastomosis of the grafts to coronary arteries was initially performed distally among all patients. Proximal anastomosis to ascending aorta was performed immediately after finishing each distal anastomosis. The sequence by which coronary vessels were grafted varied from one patient to another. Grafting of the LAD by left internal mammary artery was the first to be performed. However, in some patients with huge hearts, grafting of diagonal followed by RCA and circumflex arteries was usually performed first, leaving the LAD at the end to avoid stretching and kinking of LIMA during rotation of the heart.

Anastomosis was facilitated by the use of both U-shaped stabilizer (Guidant, Indianapolis, IN) and suction stabilizers (Medtronic Octopus III). Revascularization of circumflex or obtuse marginal arteries was performed with the help of Starfish apical positioning device (Medtronic, Inc, Minneapolis, MN). Intracoronary shunts (Medtronic Inc.) were used when needed.

\section{Results}

Preoperative patients profile and risk factors are listed in table 1. There was no differences among both groups, except for the number of patients undergoing redo CABG, which was significantly higher among ONCAB/ BH $(13 \%$ Vs $3 \%, P=0.025)$. Predicted risk for surgical intervention according to EuroSCORE was similar among both groups $(\mathrm{P}=0.443)$.

Ejection fraction (EF) among all patients was below 0.35 . It varied from 10-34. The mean EF for ONCAB/ $\mathrm{BH}$ was $28 \pm 6$ in comparison to $26 \pm 5$ for OPCAB $(P=0.093)$. The incidence of main stem involvement was more among ONCAB/BH patients, but the difference did not reach statistical significance ( $8 \%$ Vs $4 \%$, $\mathrm{P}=0.765$ ).

The extent of preoperative coronary artery disease was similar among both groups regarding the involvement of LAD, circumflex, second diagonal and obtuse marginal coronary arteries. The extent of right coronary artery disease was significantly higher among OPCAB $(70 \% \mathrm{Vs}$ $51 \% \mathrm{P}=0.025)$. On the other hand, involvement of first diagonal coronary artery was significantly higher among $\mathrm{ONCAB} / \mathrm{BH}$ (33\% Vs $17 \%, \mathrm{P}=0.035)$. There was no difference regarding the number of coronary vessels affected whether single, double or triple vessel among both groups $(\mathrm{P}=0.396)$.

There was a significant difference regarding the number of grafts used per patient among both groups (Table 2). ONCAB/BH patients received $2.2 \pm 0.7$ grafts, while OPCAB had $1.7 \pm 0.7(\mathrm{P}=0.002)$. The difference was due to more grafting of the right and circumflex coronary arteries.

Hospital mortality was slightly more among ONCAB/ $\mathrm{BH}$ patients, but the difference was not significant $8 \%$ Vs $6 \%, P=0.712$ (Table 3). The incidence of total major morbidity was more among $\mathrm{ONCAB} / \mathrm{BH}$ patients, but the difference did not reach statistical significance $(\mathrm{P}=$ 0.778). However, the incidence of blood loss, ventricular arrythmias and inotropic support were significantly greater among ONCAB/BH group. Transfusion of red blood cells and its products were significantly greater among $\mathrm{ONCAB} / \mathrm{BH}, \mathrm{P}=0.001$ (Figure 1). Postoperative intensive care unit length of stay was significantly higher in the $\mathrm{ONCAB} / \mathrm{BH}$ patients $(35 \pm 20$ hours vs $27 \pm 14$ hours for $\mathrm{OPCAB}, \mathrm{P}=0.019)$. Similarly, postoperative hospital stay was significantly higher in the ONCAB/BH patients $(7.1 \pm 2.9$ days Vs $5.9 \pm 2.3$ days for OPCAB, $\mathrm{P}=0.015)$.

\section{Discussion}

Conventional non-beating heart on-pump is still the standard technique used in coronary artery surgery. Complications in relation to this technique are due to the release of inflammatory mediators, the use of 
Table 1 Preoperative Demographics and Risk Factors

\begin{tabular}{|c|c|c|c|}
\hline Variable & On-pump BH $(n=39)$ & Off-pump BH $(n=98)$ & $P$ value \\
\hline Age & $58 \pm 8$ & $57 \pm 10$ & 0.100 \\
\hline Female gender & $7(18 \%)$ & $14(14 \%)$ & 0.826 \\
\hline BMl & $27.6 \pm 4.5$ & $28.2 \pm 4.5$ & 0.564 \\
\hline Family History of CAD & 19 (49\%) & $61(62 \%)$ & 0.128 \\
\hline Hypertension & 17 (44\%) & $49(50 \%)$ & 0.354 \\
\hline Diabetes mellitus & $18(46 \%)$ & $45(46 \%)$ & 0.929 \\
\hline Current smoker & $22(56 \%)$ & $63(64 \%)$ & 0.362 \\
\hline Dyslipidemia & $14(36 \%)$ & $41(42 \%)$ & 0.598 \\
\hline Obesity & $12(31 \%)$ & $28(27 \%)$ & 0.778 \\
\hline Peripheral vascular disease & $3(8 \%)$ & $8(8 \%)$ & 0.814 \\
\hline Carotid artery disease & $5(13 \%)$ & $12(12 \%)$ & 0.387 \\
\hline Urgent operation & $8(21 \%)$ & $28(29 \%)$ & 0.319 \\
\hline COPD & $6(15 \%)$ & $15(15 \%)$ & 0.753 \\
\hline Redo CABG & $5(13 \%)$ & $3(3 \%)$ & 0.025 \\
\hline Chronic Kidney Disease & $6(15 \%)$ & $11(11 \%)$ & 0.126 \\
\hline Recent Angioplasty & $6(15 \%)$ & $17(17 \%)$ & 0.884 \\
\hline Myocardial Infarction & $26(67 \%)$ & $65(66 \%)$ & 0.600 \\
\hline Heart Failure & $12(31 \%)$ & $52(53 \%)$ & 0.241 \\
\hline Unstable Angina & $22(56 \%)$ & $43(44 \%)$ & 0.082 \\
\hline Stroke & $5(13 \%)$ & $6(6 \%)$ & 0.381 \\
\hline Streptokinase & $6(15 \%)$ & $5(5 \%)$ & 0.126 \\
\hline Clopidogrel & $6(15 \%)$ & $8(8 \%)$ & 0.273 \\
\hline EuroSCORE & $14.1 \pm 11.0$ & $12.2 \pm 12.5$ & 0.443 \\
\hline
\end{tabular}

cardioplegia, aortic cross clamping and hypothermia [4]. Off-pump technique was introduced to avoid such complications. Despite its efficiency and safety over conventional $\mathrm{CPB}$, the technique was criticized by many investigators regarding completeness of myocardial revascularization, graft patency and long term results. One of the important draw backs of this technique is

Table 2 Operative Data

\begin{tabular}{lccc}
\hline Variable & On-pump BH & Off-pump BH & P value \\
\hline Use of LIMA & $30(77 \%)$ & $73(75 \%)$ & 0.827 \\
\hline Use of RIMA & $1(3 \%)$ & $2(2 \%)$ & 0.835 \\
\hline LAD Graft & $37(95 \%)$ & $95(97 \%)$ & 0.544 \\
\hline RCA Graft & $9(23 \%)$ & $19(19 \%)$ & 0.581 \\
\hline PDA Graft & $4(10 \%)$ & $4(5 \%)$ & 0.019 \\
\hline D1 Graft & $13(33 \%)$ & $16(16 \%)$ & 0.381 \\
\hline D2 graft & $9(23 \%)$ & $26(27 \%)$ & 0.022 \\
\hline OM1 Graft & $3(8 \%)$ & $3(3 \%)$ & 0.221 \\
\hline OM2 Graft & $1(3 \%)$ & $0(0 \%)$ & 0.109 \\
\hline CX Graft & $7(18 \%)$ & $4(4 \%)$ & 0.182 \\
\hline Operation Time & $4.0 \pm 1.0$ & $3.7 \pm 1.0$ & 0.033 \\
\hline Number of grafts & $2.2 \pm 0.7$ & $1.7 \pm 0.7$ & 0.002 \\
\hline Complete revascularization & $28(72 \%)$ & $45(46 \%)$ & 0.015 \\
\hline
\end{tabular}

the hemodynamic deterioration which can occur during manipulation of the heart during surgery, which entails urgent transfer to conventional CPB. The results of such surgery proved to be inferior [5].

From our previous study [1] using off-pump bypass among low ejection fraction patients, we found that such a technique is effective in reducing both mortality and morbidity. Nevertheless, we agree with other

Table 3 Postoperative Morbidity and Mortality

\begin{tabular}{llll}
\hline Variable & On-pump BH & Off-pump BH & P value \\
\hline 30-Day Mortality & $3(8 \%)$ & $6(6 \%)$ & 0.712 \\
\hline Morbidity & $12(31 \%)$ & $26(27 \%)$ & 0.778 \\
\hline Infection & $4(10 \%)$ & $4(4 \%)$ & 0.765 \\
\hline Atrial Fibrillation & $3(8 \%)$ & $8(8 \%)$ & 0.959 \\
\hline Ventricular Arrhythmias & $9(23 \%)$ & $4(4 \%)$ & 0.002 \\
\hline Myocardial infarction & $5(13.15 \%)$ & $8(8 \%)$ & 0.192 \\
\hline CVA & $1(3 \%)$ & $1(1 \%)$ & 0.535 \\
\hline Respiratory Failure & $3(8 \%)$ & $1(1 \%)$ & 0.133 \\
\hline Renal Failure & $3(8 \%)$ & $3(3 \%)$ & 0.221 \\
\hline Intra Aortic Balloon pump & $7(18 \%)$ & $10(10 \%)$ & 0.196 \\
\hline Inotropic Support & $31(79 \%)$ & $29(30 \%)$ & 0.001 \\
\hline Estimated blood loss & $974 \pm 824$ & $548 \pm 337$ & 0.001 \\
\hline
\end{tabular}




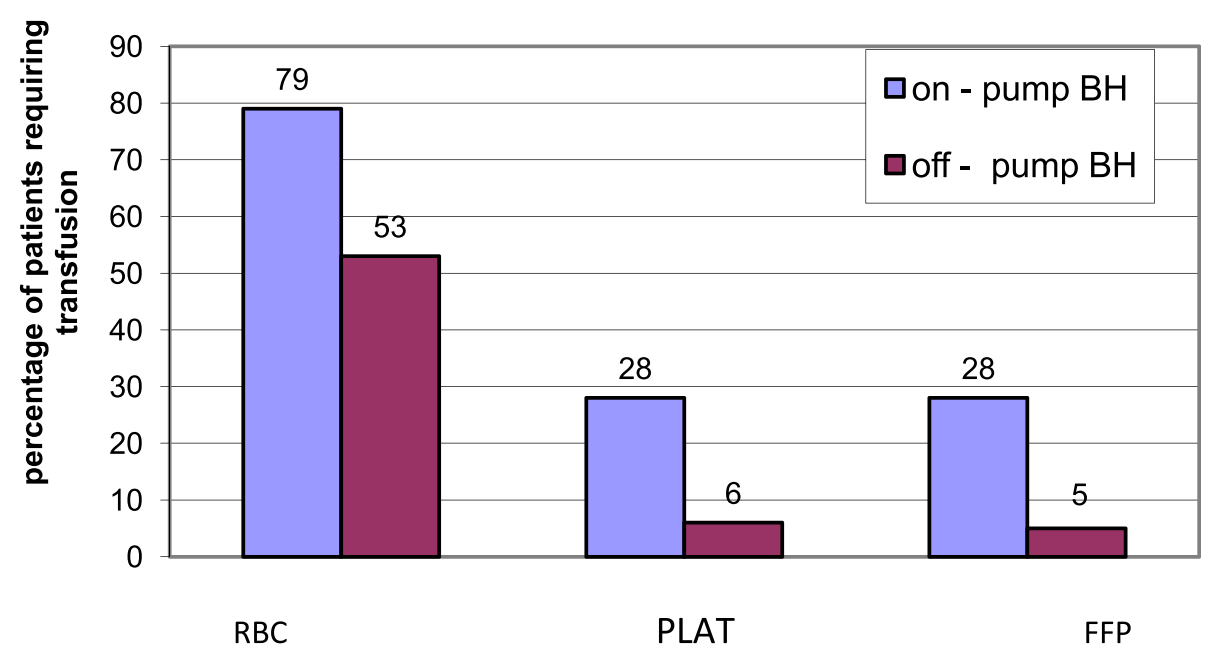

Figure 1 Percentage of patients requiring blood transfusion and its products. RBC: Red blood cells, PLAT: Platelets, FFP: Fresh frozen plasma.

investigators that the technique is not always associated with complete revascularization. The main obstacle which determines completeness of revascularization is the hemodynamic deterioration which can occur during such a procedure. To avoid such deterioration among our patients, we advocated minimal manipulation during surgery which obviously lead to less number of grafts used and incomplete revascularization.

An intermediatory approach between conventional and off-pump bypass was studied by Perrault and colleagues [3]. They used on-pump beating heart (ONCAB/BH) among their patients with low ejection fraction. They found that using $\mathrm{CPB}$ without cross clamping and cardioplegic arrest with the heart beating is associated with less myocardial oedema and ischemia. From their study, they proved that such a technique is effective in preventing myocardial injury and can be effectively used among high risk patients who cannot tolerate cardioplegic arrest or when the use of off-pump is not technically feasible.

Since the work of Perrault, various studies using $\mathrm{ONCAB} / \mathrm{BH}$ technique for myocardial revascularization among both low and high risk patients was performed [4,6-15]. The technique proved to be a reliable and effective method and was associated with complete revascularization.

The main idea of using $\mathrm{ONCAB} / \mathrm{BH}$ technique among high risk patients is to avoid the serious manipulation which could be harmful to the myocardium and subsequently to perform complete revascularization. Surprisingly, in our study, we found that the incidence of myocardial infarction was more among patients who underwent $\mathrm{ONCAB} / \mathrm{BH}$ when compared to OPCAB, which indicates that manipulation of the heart even when supported by the bypass machine is still harmful.
In an interesting study performed by Rastan and coworkers[4] using $\mathrm{ONCAB} / \mathrm{BH}$ among patients with normal ejection fraction, they found an increase incidence of myocardial injury when compared to off-pump. Although, the effect was without any clinical significance they believed that such a technique is not favourable to off-pump bypass. Pegg and co-workers[12], confirmed these findings, by reporting that that the incidence of new irreversible myocardial injury among patients with impaired LVF was significantly higher among ONCAB/ $\mathrm{BH}$ patients when compared with conventional bypass.

The other benefit of using $\mathrm{ONCAB} / \mathrm{BH}$ is to achieve complete revascularization. Previous studies showed that this technique was associated with adequate number of grafts performed among both low and high risk patients $[3,6,9,10,14,15]$. Comparing the number of grafts performed to other bypass techniques, conflicting results were obtained. Some studies were in favour of off-pump and conventional bypass over ONCAB/BH $[4,7,14]$, while others were in favour of $\mathrm{ONCAB} / \mathrm{BH}$ when compared to other techniques of bypass [9]. Prifti and colleagues in their study [11], found a similar number of grafts performed among both conventional and $\mathrm{ONCAB} / \mathrm{BH}$. We agree with previous studies that $\mathrm{ONCAB} / \mathrm{BH}$ technique is associated with adequate number of grafts performed. In our present study, there was a significant difference in the number of grafts performed and complete revascularization was in favour of $\mathrm{ONCAB} / \mathrm{BH}$. The main reason for such a difference was due to difficulty in grafting of circumflex and posterior descending coronary arteries among patients undergoing off-pump bypass.

The mortality rate of patients with impaired LVF undergoing $\mathrm{ONCAB} / \mathrm{BH}$ varies from $2-8 \%[6,10,11,15]$. 
The difference in mortality among various studies was directly related to the difference in selection of patients. Beside impaired LVF, other associated risk factors were involved, as acute myocardial infarction, cardiogenic shock and patients on dialysis $[7,8,15]$. In our study, the mortality rate was $7.7 \%$, which was high compared to other studies. The high mortality among our group of patients was related to the impaired left ventricular function. Other factors contributing to the mortality of patients were the preoperative association of heart failure and myocardial infarction, the failure to revascularize both circumflex artery in $15 \%$ and RCA in $8 \%$ of patients and lower percentage of patients who received LIMA for grafting. Comparing our results with Folliguet and colleagues study[6], they had the lowest mortality among their group of patients despite a similar mean ejection fraction to our patients, we found that the mean EuroSCORE of their patients was $5.8 \pm 2.7$ in comparison to $14.1 \pm 11.0$ among our patients. This clearly shows the importance of associated other risk factors affecting mortality beside impaired LVF.

There are limited studies evaluating the incidence of mortality in relation to using either $\mathrm{ONCAB} / \mathrm{BH}$ or offpump. Among low risk patients, the mortality rate among patients who had ONCAB/BH was higher than off-pump bypass [9]. On the contrary, in Rastan and colleagues study [4] the mortality rate was more among off-pump bypass patients. In high risk groups, Edgerton and colleagues [8] found that mortality rate was significantly higher among ONCAB/BH patients when compared to off-pump. Similar findings were seen in our study. However, the differences in mortality among our two groups of patients was not significant.

From the above limited studies, it seems that $\mathrm{ONCAB} / \mathrm{BH}$ is associated with more mortality than OPCAB despite the fact that these patients have adequate myocardial revascularization. The explanation for such unexpected results is related to the use of bypass machine. Early work by Perrault and co-workers [3] found that the release of inflammatory mediators interleukin-6, interleukin-10 and elastase among patients undergoing on-pump $\mathrm{BH}$ was not significantly different from conventional bypass. A further study [13] found that $\mathrm{ONCAB} / \mathrm{BH}$ can trigger an intense inflammatory response, they found that the levels of interleukin-6, interleukin-8, interleukin-10 and tumour necrosis factor-alpha were significantly elevated when compared to off-pump bypass.

It seems that $\mathrm{ONCAB} / \mathrm{BH}$ technique does not ameliorate the complications encountered with the use of bypass machine and its effect among high risk patients. This is the basic difference from off-pump bypass technique. In our study, the number of patients who had postoperative major morbidity were higher among
$\mathrm{ONCAB} / \mathrm{BH}$ patients when compared to OPCAB technique. The percentage of patients who had postoperative renal failure, infarction, use of inotropic support and IABP were less among off-pump patients. The amount of blood loss and ventricular arrythmias were significantly higher among ONCAB/BH patients. This was reflected on the significant amount of blood transfusion, blood products and longer ventilation time, intensive care and hospital stay.

The application of ONCAB/BH among patients with impaired LVF resulted in conflicting data. Although, patients had significantly better myocardial revascularization, the incidence of mortality and morbidity was more than OPCAB. It seems that ONCAB/BH technique gives a false sense of security believing that the use of bypass machine can protect the heart during manipulation to perform a better revascularization. This could be true among low risk patients, but the scenario is different when the technique is applied to high risk group.

The present study is one of few studies comparing two technique used in myocardial revascularization among patients with impaired LVF. The study carries several limitations, being a retrospective study among a small number of patients, which made the validity of the clinical results limited. Further studies are needed in particular to follow up these patients to find out the benefit which was achieved by increasing myocardial revascularization among patients who underwent on-pump beating heart.

In conclusion, we believe that $\mathrm{ONCAB} / \mathrm{BH}$ can be used in myocardial revascularization among patients with left ventricular dysfunction. The technique was found to be associated with better myocardial revascularization, more morbidity and mortality when compared to off-pump bypass.

\section{Author details}

'Department of Cardiac Surgery, Makassed Hospital, Jerusalem, Israel. ${ }^{2}$ Department of Cardiology, Makassed Hospital, Jerusalem, Israel.

\section{Authors' contributions}

AKD Performed operations, conception and study design. VB Assist in surgical procedures and acquisition of data. II and KH investigations and follow up of patients. All were involved in interpretation of data and statistical analysis. All authors read and approved the final manuscript.

\section{Competing interests}

The authors declare that they have no competing interests.

Received: 13 July 2010 Accepted: 10 November 2010

Published: 10 November 2010

\section{References}

1. Darwazah AK, Abu Sham'a RA, Hussein E, Hawari MH, Ismail H: Myocardial revascularization in patients with low ejection fraction $<$ or $=35 \%$ : effect of pump technique on early morbidity and mortality. J Card Surg 2006, 21:22-27.

2. Youn YN, Chang BC, Hong YS, Kwak YL, Yoo KL: Early and mid-term impacts of cardiopulmonary bypass on coronary artery bypass grafting 
in patients with poor left ventricular dysfunction: a propensity score analysis. Circ J 2007, 71:1387-1394.

3. Perrault LP, Menaschè P, Peynet J, Faris $B$, Bel $A$, de Chumaray $T$, Gatecel $C$, Touchot B, Bloch G, Moalic JM: On-pump, Beating-Heart Coronary Artery Operations in High-Risk Patients: An Acceptable Trade-off? Ann Thorac Surg 1997, 64:1368-73.

4. Rastan AJ, Bittner HB, Gummert JF, Wather T, Schewick CV, Girdauskas E, Mohr FW: On-pump beating heart versus off-pump coronary artery bypass surgery-evidence of pump-induced myocardial injury. Eur $J$ Cardiothorac Surg 2005, 27:1057-1064.

5. Legare JF, Buth $\mathrm{K}$, Hirsh GM: Conversion to on pump from OPCAB is associated with increased mortality: results from a randomised controlled trial. Eur J Cardiothorac Surg 2005, 27:296-301.

6. Folliguet TA, Philippe F, Larrazet F, Dibie A, Czitrom D, Le Bret E, Bachet J, Laborde F: Beating heart revascularization with minimal extracorporal circulation in patients with a poor ejection fraction. Heart Surg Forum 2002, 6(1):19-23.

7. Miyahara K, Matsuura A, Takemura H, Saito S, Sawaki S, Yoshioka T, Ito H: On-pump beating-heart coronary artery bypass grafting after acute myocardial infarction has lower mortality and morbidity. I Thorac Cardiovasc Surg 2008, 135(3):521-6.

8. Edgerton JR, Herbert MA, Jones KK, Prince SL, Acuff T, Carter D, Dewey T, Magee M, Mack M: On-pump Beating Heart Surgery offers an Alternative for unstable patients undergoing coronary Artery Bypass grafting. Heart Surg Forum 2004, 7(1):8-15.

9. Uva MS, Rodrigues V, Monteiro N, Pereira F, Bervens D, Caria R, Mesquita A, Perdro A, Bau J, Matias F, Magalhaes MP: Coronary surgery: which method to use? Rev Port Cardiol 2004, 23(4):517-30.

10. Gulcan O, Turkoz R, Turkoz A, Caliskan E, Sezgin AT: On-pump/beatingheart myocardial protection for isolated or combined coronary artery bypass grafting in patients with severe left ventricular dysfunction: assessment of myocardial function and clinical outcome. Heart Surg Forum 2005, 8(3):E189-82

11. Prifti E, Bonacchi M, Giunt G, Frati G, Proietti P, leacche M, Salica A, Sani G, Branaccio G: Does on-pump/beating - heart coronary artery bypass grafting offer better outcome in end-stage coronary artery disease patients? J Card Surg 2000, 15(6):403-10.

12. Pegg TJ, Selvanayegam JB, Francis JM, Karamitsos TD, Maunsell Z, Yu LM, Neubauer S, Taggart DPA: Randomized Trial of on-pump Beating heart and conventional cardiopelgic arrest in Coronary artery Bypass Surgery patients with impaired left ventricular Function using cardiac Magnetic Resonance Imaging and Biochemical Markers. Circulation 2008, 118:2130-2138.

13. Wan IY, Arifi AA, Wan S, Yip JH, Sihoe AD, Thung KH, Wong EM, Yim AP: Beating heart revascualrization with without cardiopulmonary bypass: evaluation of inflammatory response in a prospective randomised study. J Thorac Cardiovasc Surg 2004, 127(6):1624-31.

14. Mizutani S, Matsuura A, Miyahara K, Eda T, Kawamura A, Yoshioka T, Yoshida K: On-pump Beating-Heart Coronary artery Bypass: A propensity Matched Analysis Ann Thorac Surg. 2007, 83(4):1368-1373.

15. Ferrari E, Stalder N, von Segesser LK: On-pump beating heart coronary surgery for high risk patients requiring emergency multiple coronary artery bypass grafting. J Cardiothorac Surg 2008, 3:38.

doi:10.1186/1749-8090-5-109

Cite this article as: Darwazah et al: Myocardial revascularization using on-pump beating heart among patients with left ventricular dysfunction. Journal of Cardiothoracic Surgery 2010 5:109.

\section{Submit your next manuscript to BioMed Central and take full advantage of:}

- Convenient online submission

- Thorough peer review

- No space constraints or color figure charges

- Immediate publication on acceptance

- Inclusion in PubMed, CAS, Scopus and Google Scholar

- Research which is freely available for redistribution

Submit your manuscript at www.biomedcentral.com/submit
Biomed Central 